\title{
Article \\ Sex Difference in the Association between Electronic Cigarette Use and Subsequent Cigarette Smoking among U.S. Adolescents: Findings from the PATH Study Waves 1-4
}

\author{
Zongshuan Duan (1), Yu Wang (1) and Jidong Huang *(i) \\ School of Public Health, Georgia State University, Atlanta, GA 30303, USA; zduan3@student.gsu.edu (Z.D.); \\ ywang145@student.gsu.edu (Y.W.) \\ * Correspondence: jhuang17@gsu.edu; Tel.: +1-404-413-9337
}

check for updates

Citation: Duan, Z.; Wang, Y.; Huang, J. Sex Difference in the Association between Electronic Cigarette Use and Subsequent Cigarette Smoking among U.S. Adolescents: Findings from the PATH Study Waves 1-4. Int. J. Environ. Res. Public Health 2021, 18, 1695. https://doi.org/10.3390/ ijerph18041695

Academic Editors: Mary Hrywna, Ollie Ganz and Adam Cole Received: 22 December 2020 Accepted: 8 February 2021 Published: 10 February 2021

Publisher's Note: MDPI stays neutral with regard to jurisdictional claims in published maps and institutional affiliations.

Copyright: (c) 2021 by the authors. Licensee MDPI, Basel, Switzerland. This article is an open access article distributed under the terms and conditions of the Creative Commons Attribution (CC BY) license (https:// creativecommons.org/licenses/by/ $4.0 /)$.

\begin{abstract}
E-cigarettes are the most-used tobacco products among U.S. adolescents. Emerging evidence suggests that adolescents using e-cigarettes are at elevated risk for initiating cigarette smoking. However, whether this risk may differ by sex remains unknown. This study analyzed data from Wave 1 to 4 of the Population Assessment of Tobacco and Health (PATH) Study, a nationally representative longitudinal survey. Generalized estimation equations (GEE) were performed to estimate the associations between baseline e-cigarette use and subsequent cigarette smoking, controlling for sociodemographic characteristics, mental health conditions, and other tobacco use. Effect modifications by sex were examined. Multivariate analyses showed that, among baseline never cigarette smokers, past-30-day e-cigarette use at baseline waves was significantly associated with past-30-day cigarette smoking at follow-up waves $(\mathrm{aOR}=3.90,95 \% \mathrm{CI}$ : 2.51-6.08). This association was significantly stronger for boys ( $\mathrm{aOR}=6.17,95 \% \mathrm{CI}$ : 2.43-15.68) than for girls (aOR $=1.10,95 \% \mathrm{CI}: 0.14-8.33$ ). Additionally, using other tobacco products, older age, and having severe externalizing mental health problems at baseline were significantly associated with an increased likelihood of cigarette smoking at follow-up. The prospective association between e-cigarette use and cigarette smoking differs by sex among U.S. adolescents. Sex-specific tobacco control interventions may be warranted to curb the youth tobacco use epidemic.
\end{abstract}

Keywords: adolescents; electronic cigarettes; cigarettes; sex difference; youth tobacco prevention

\section{Introduction}

Cigarette smoking among U.S. youth has declined substantially since the mid-1990s [1]. Among 12th-grade students, the prevalence of past-30-day (P30D) cigarette smoking decreased steadily from $28.3 \%$ in 1996 to $7.5 \%$ in 2020 [2,3]. However, e-cigarettes are becoming increasingly popular among adolescents, including those who are not susceptible to smoking cigarettes [4-6]. In 2020, 19.6\% of high school students and $4.7 \%$ of middle school students reported using e-cigarettes in the past 30 days [7]. A growing body of evidence documented a positive association between e-cigarette use and subsequent cigarette smoking initiation among tobacco-naïve adolescents [8-10], leading to concerns that the increased e-cigarette use among youth may potentially addict a new generation to combustible cigarettes, resulting in a lifetime nicotine addiction [4]. A recent meta-analysis combined the findings of 9 longitudinal studies and reported that, among youth and young adults, the pooled adjusted odds ratio (aOR) for subsequent cigarette smoking initiation was 3.62 (95\% CI, 2.42-5.41) among ever e-cigarette users compared with never e-cigarette users. In addition, it found that the pooled aOR for P30D cigarette smoking at follow-up was 4.28 (95\% CI, 2.52-7.27) among baseline P30D e-cigarette users compared with those who did not use e-cigarettes in the past 30 days at baseline [8].

Despite the growing number of studies investigating the prospective relationships between adolescent e-cigarette use and subsequent cigarette smoking, no study had ex- 
amined how this association may differ by sex. The tobacco use behaviors and nicotine addiction among adolescents are dependent upon their sex [11]. Unfortunately, to date, tobacco control policies and interventions have remained largely sex blind, with limited recognition of the importance of understanding the sex differences in the mechanism and consequences of tobacco products' initiation and transition [11,12]. Sex is a significant dimension for nearly all public health areas [13], and tobacco use is no exception. Evidence from laboratory experiments with non-human subjects indicated that the neurobiological mechanisms underlying nicotine seeking and metabolism differ between males and females [14,15]. Due to the presence of higher level of estrogen, females metabolize nicotine faster and experience lower rewarding effects of nicotine than males [16]. Therefore, while men were more likely to smoke for the reinforcing stimulant effects of nicotine, women were more likely to smoke for other reasons, such as emotion regulation and reaction to nicotine-related cues [17]. Additionally, a meta-analysis based on social studies revealed that the norms associated with adolescent boys and girls, and the sex composition of adolescents' social networks might differentially affect their tobacco adoption and use behaviors [18]. In general, the traditional social norms placed more restrictions on women's tobacco use behaviors, and the norms also contributed to social pressures and expectations against women's smoking behaviors [18-20]. Due to variations in the factors contributing to sex differences in tobacco use, adolescent girls who use e-cigarettes may have different patterns of transitioning to cigarette smoking, compared with their male counterparts. Consequently, the general associations between e-cigarette use and subsequent cigarette initiation reported in previous studies may mask important sex differences, resulting in inaccurate predictions of the impacts of policies and interventions aiming to curb adolescent tobacco use.

In addition to the important knowledge gap regarding the potential sex difference, many previous studies did not control for the effect of mental health conditions, which were found to be associated with the initiation of tobacco use among adolescents [21-23]. Our study aims to address these critical research gaps. Specifically, we used the youth cohort from the first four waves of the Population Assessment of Tobacco and Health (PATH) Study to investigate whether the longitudinal association between initial e-cigarette use and subsequent cigarette smoking initiation would differ by sex, controlling for individual's sociodemographic characteristics, use of other tobacco products, and mental health conditions. We hypothesize that this association would differ by sex. Additionally, we hypothesize that significant differences exist in cigarette smoking initiation between subgroups characterized by individual factors.

\section{Materials and Methods}

\subsection{Study Sample and Design}

Data were collected from 2013 through 2018 and analyzed in 2020. This study used a youth cohort sample (aged 12-17) compiled from Wave 1 (September 2013 to December 2014), Wave 2 (October 2014 to October 2015), Wave 3 (October 2015 to October 2016), and Wave 4 (December 2016 to January 2018) of the PATH Study, an ongoing nationally representative cohort study conducted by the U.S. National Institutes of Health (NIH) and the Food and Drug Administration (FDA) [24,25]. A four-stage stratified probability sample was selected to represent the noninstitutionalized population in the U.S. [25]. Among households that were screened, the weighted response rates for the youth cohort were $78.4 \%$ (Wave 1), $87.3 \%$ (Wave 2), 83.3\% (Wave 3), and 79.5\% (Wave 4), respectively [26,27]. In the PATH data, multiple imputations were performed on the variables such as sex, age, and use of tobacco products to address the missing data bias. Details regarding the PATH study design and sampling methods are published elsewhere [25], and are described in the PATH Study Public-Use Files user guide [26]. This study involved only secondary data analysis of the PATH survey data, which contained no personally identifiable information, and was exempt for ethical review by the Georgia State University Institutional Review Board (IRB Number: H20183; Reference Number: 357029). This article follows the reporting 
guideline for cohort studies of the Strengthening the Reporting of Observational Studies in Epidemiology (STROBE) [28].

In this study, we followed a validated approach used by the data management and research team of the PATH study to stack covariates in the baseline wave with cigarette smoking status at its corresponding follow-up wave study [29-31]. In this study, Wave 1 , Wave 2, and Wave 3 were each considered as the baseline wave for its corresponding 12-month follow-up wave. The youth all-wave weights for the Wave 1 cohort were used to produce nationally representative estimates. The all-wave weights were assigned only to Wave 1 respondents and the shadow sample of individuals aged 9-11 at Wave 1 who completed interviews at all waves while they were 12-17 years old [27]. The target population of this study included youth respondents who reported never having used cigarettes at baseline waves. At each baseline wave, participants were asked, "Have you ever tried cigarette smoking, even one or two puffs", and those who responded "No" were identified as baseline never cigarette smokers.

\subsection{Measures}

The primary outcome was the self-reported P30D cigarette smoking status at 12month follow-up waves among never cigarette smokers at baseline waves. In the follow-up surveys, baseline never cigarette smokers who reported smoking at least one cigarette in the past 30 days at follow-up waves were coded as P30D cigarette smokers. Additionally, respondents who tried cigarette smoking, even one or two puffs in between baseline and 12-month follow-up, were defined as ever cigarette smokers.

The primary exposure variable was the P30D use of e-cigarettes at baseline waves. In each baseline wave, never cigarette smokers who reported having used any e-cigarettes in the past 30 days were categorized as baseline P30D users of e-cigarettes.

Covariates were potential confounding variables selected based on previous literature $[8,10,29,32]$, including the following two domains. (1) Sociodemographic factors and other tobacco products use status at baseline waves: age (12-14 or 15-17), sex (male or female), race/ethnicity (Hispanic, Non-Hispanic White, Non-Hispanic Black, or NonHispanic Other), parental education (less than high school, high school graduate, some college or associate degree, and bachelor's degree or above), and P30D use of other tobacco products (defined as using cigar, hookah, or smokeless tobacco in the past 30 days). Sexual orientation (straight vs. homosexual, bisexual, or other), which was only available for participants aged 14 and above, was used to examine the bivariate associations with outcome variables but not included in the regression analysis. (2) Intrapersonal factors: the internalizing and externalizing mental health problems over the past 12 months at baseline waves. The PATH study included four items measuring internalizing problems and seven items measuring externalizing problems (Table S1). In this study, we followed a validated approach to sum up the scores for internalizing and externalizing problems, where the severity of mental health problems was categorized into low (0-1), moderate (2-3), and high severity ( 4 for internalizing problems or $4-7$ for externalizing problems) $[33,34]$.

\subsection{Statistical Analysis}

All data management and analyses were conducted using Stata 15 (StataCorp LLC. College Station, TX, USA). The youth cohort all-wave weights were applied to account for the complex sample design features and to produce nationally representative estimates. The balanced repeated replication (BRR) approach with Fay's adjustment of 0.3 was used to compute statistical precision for all estimations [25,29]. We reported the weighted prevalence of outcomes at follow-up waves and their weighted associations with covariates at baseline waves. Generalized estimating equations (GEE) with unstructured covariance were used to estimate the associations between the outcomes and exposure variables, controlling for individual sociodemographic characteristics, use of other tobacco products, and mental health conditions. Additional GEE models were fitted to examine the potential effect modifications of sex on the association between P30D e-cigarette use at baseline 
and P30D cigarette smoking at 12-month follow-up. Subgroup analyses, separately for adolescent boys and girls, were conducted to compare the associations between e-cigarette use and subsequent cigarette smoking. Additionally, sensitivity analyses, based on the same set of analyses mentioned above, in which the outcome measures were replaced with ever cigarette smoking, were conducted. All statistical tests were two-sided with the significance level set to 0.05 .

\section{Results}

\subsection{Sample and Demographic Characteristics}

Our study sample included 5001 youth never cigarette smokers at Wave 1, 6637 at Wave 2, and 8177 at Wave 3. The enrollment and exclusion procedures are illustrated in Figure 1.

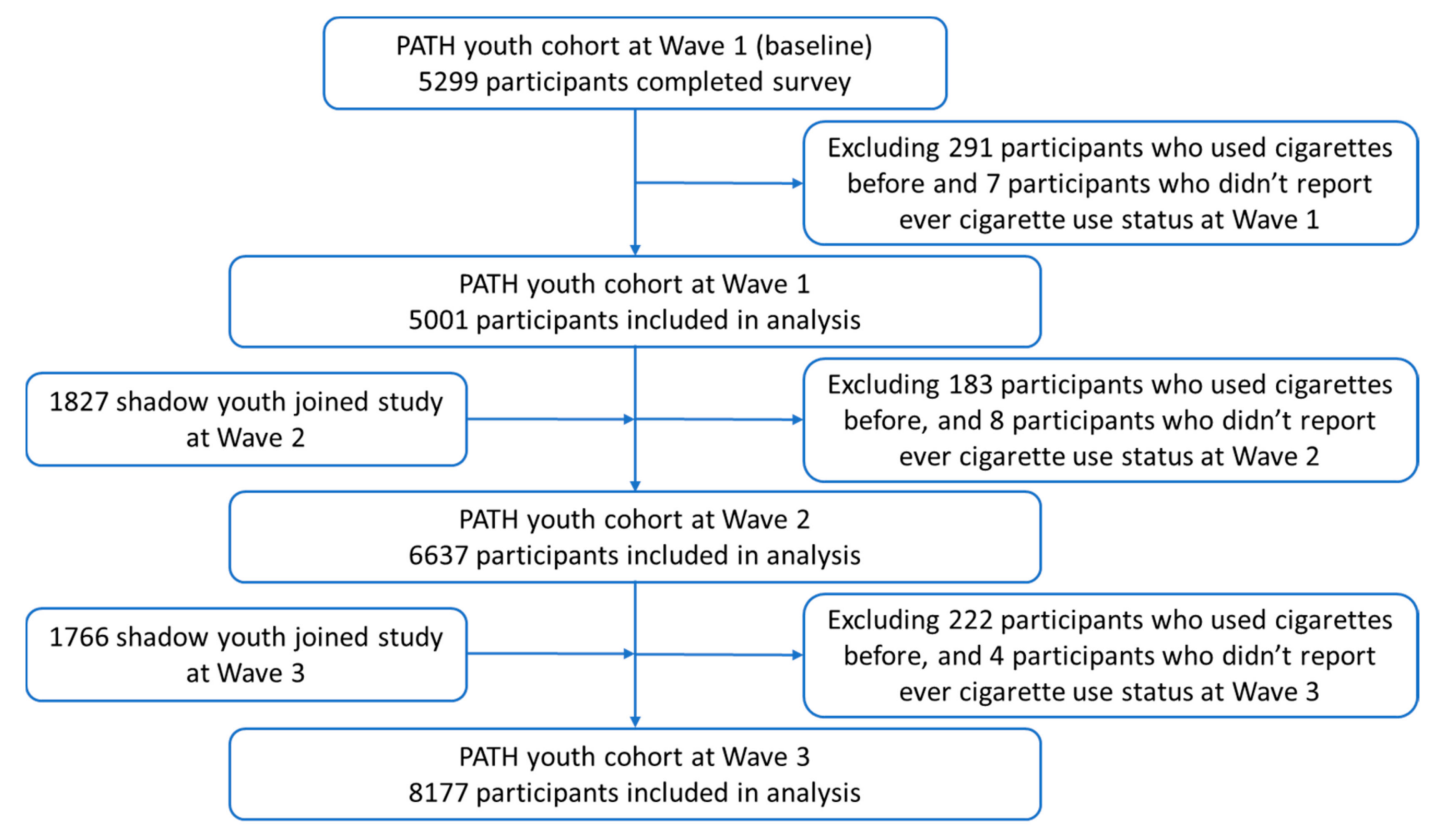

Figure 1. Flowchart for participants included in final analysis.

Among youth who reported never having used cigarettes at Wave 1, the weighted prevalence of P30D e-cigarette use was $0.4 \%$; almost all (96.7\%) respondents were between age 12 and $14 ; 49.2 \%$ of the respondents were girls; $53.4 \%$ were Non-Hispanic White, $14.4 \%$ were Non-Hispanic Black, and $23.0 \%$ were Hispanic; $0.4 \%$ used other tobacco products in the past 30 days; and $18.1 \%$ and $29.5 \%$ of them experienced high severity of internalizing and externalizing mental health problems in the past year, respectively. Among youth who reported never having used cigarettes at Wave 2, $0.9 \%$ of them used e-cigarette in the past 30 days; over three quarters $(77.0 \%)$ of them were between age $12-14 ; 49.2 \%$ were girls; $52.5 \%$ were Non-Hispanic White, $13.9 \%$ were Non-Hispanic Black, and $23.9 \%$ were Hispanic; $0.6 \%$ used other tobacco products in the past 30 days; and $19.7 \%$ and $28.8 \%$ experienced high severity of internalizing and externalizing mental health problems in the past year, respectively. Among youth who reported never having used cigarettes at Wave 3 , $1.5 \%$ used e-cigarette in the past 30 days; approximately two thirds of them were between age $12-14 ; 48.9 \%$ were girls; $51.7 \%$ were Non-Hispanic White, $13.6 \%$ were Non-Hispanic Black, and $24.6 \%$ were Hispanic; $0.7 \%$ used other tobacco products in the past 30 days; and $21.3 \%$ and $29.1 \%$ experienced high severity of internalizing and externalizing mental health problems in the past year, respectively. Detailed descriptive statistics of other characteristics are presented in Table 1. 
Table 1. Descriptive statistics of covariates at baseline waves among adolescents (12-17 years of age) who reported never having smoked cigarettes.

\begin{tabular}{|c|c|c|c|}
\hline & Wave $1(n=5001)$ & Wave $2(n=6637)$ & Wave $3(n=8177)$ \\
\hline & $n(\%)$ & $n(\%)$ & $n(\%)$ \\
\hline \multicolumn{4}{|l|}{ Interview status } \\
\hline Youth (aged 12-17) & $5001(100)$ & $4864(73.3)$ & $4711(57.6)$ \\
\hline Shadow youth (aged 9-11) & $0(0)$ & $1773(26.7)$ & $3466(42.4)$ \\
\hline \multicolumn{4}{|l|}{ P30D e-cigarette use } \\
\hline Yes & $19(0.4)$ & $53(0.9)$ & $112(1.5)$ \\
\hline No & 4949 (99.6) & $6538(99.1)$ & $8033(98.5)$ \\
\hline \multicolumn{4}{|l|}{ Age group } \\
\hline $12-14$ & $4388(96.7)$ & $5147(77.0)$ & $5175(63.3)$ \\
\hline $15-17$ & $168(3.3)$ & $1490(23.0)$ & $3002(36.7)$ \\
\hline \multicolumn{4}{|l|}{ Sex } \\
\hline Male & $2551(50.8)$ & $3365(50.8)$ & $4190(51.1)$ \\
\hline Female & $2450(49.2)$ & $3253(49.2)$ & $3963(48.9)$ \\
\hline \multicolumn{4}{|l|}{ Race/ethnicity } \\
\hline Non-Hispanic White & $2334(53.4)$ & $2984(52.5)$ & $3624(51.7)$ \\
\hline Non-Hispanic Black & $722(14.4)$ & 899 (13.9) & 1087 (13.6) \\
\hline Non-Hispanic Other & $447(9.2)$ & $586(9.7)$ & $739(10.1)$ \\
\hline Hispanic & $1498(23.0)$ & $1946(23.9)$ & $2402(24.6)$ \\
\hline \multicolumn{4}{|l|}{ Sexual orientation (ages 14+) } \\
\hline Straight/Heterosexual & $1455(94.9)$ & $2867(92.3)$ & $4145(90.9)$ \\
\hline Gay, lesbian, bisexual, or other & $75(5.1)$ & $234(7.7)$ & $421(9.1)$ \\
\hline \multicolumn{4}{|l|}{ Parental education } \\
\hline Less than high school & 1009 (17.4) & $1199(16.4)$ & $1511(15.9)$ \\
\hline High school graduate & $907(17.3)$ & $1105(17.0)$ & $1392(16.4)$ \\
\hline Some college or associate degree & $1024(19.9)$ & $1882(30.3)$ & $2519(31.0)$ \\
\hline Bachelor's degree or above & $2032(45.4)$ & $1928(36.6)$ & $2583(36.7)$ \\
\hline \multicolumn{4}{|l|}{ P30D use of other tobacco products 1} \\
\hline Yes & $19(0.4)$ & $32(0.6)$ & $56(0.7)$ \\
\hline No & 4757 (99.6) & $6461(99.4)$ & $8059(99.3)$ \\
\hline \multicolumn{4}{|l|}{ Past year internalizing problems } \\
\hline Low & $2558(52.5)$ & $3420(52.6)$ & $4023(50.7)$ \\
\hline Moderate & $1432(29.4)$ & $1771(27.7)$ & $2205(28.0)$ \\
\hline High & $856(18.1)$ & $1269(19.7)$ & $1704(21.3)$ \\
\hline \multicolumn{4}{|l|}{ Past year externalizing problems } \\
\hline Low & $1901(39.8)$ & $2776(43.4)$ & $3397(43.2)$ \\
\hline Moderate & $1446(30.7)$ & $1738(27.8)$ & $2127(27.8)$ \\
\hline High & 1368 (29.5) & $1807(28.8)$ & 2249 (29.1) \\
\hline
\end{tabular}

${ }^{1}$ Other tobacco included cigars (traditional cigars, cigarillos, or filtered cigars), hookah, and smokeless tobacco (snus pouches, loose snus, moist snuff, dip, spit, or chewing tobacco).

\subsection{Past-30-Day Cigarette Smoking at 12-Month Follow-up Waves}

As shown in Table 2, among adolescents who reported P30D e-cigarette use at baseline waves, the prevalence of P30D cigarette smoking was 4.0\% (95\% CI: 0.5-27.7\%) at Wave 2, $12.6 \%$ (95\% CI: 5.1-27.6\%) at Wave 3, and 9.1\% (95\% CI: 4.9-16.4\%) at Wave 4, respectively. By contrast, among adolescents who did not use e-cigarette at baseline waves, the prevalence of P30D cigarette smoking was 1.2\% (95\% CI: 0.9-1.6\%) at Wave 2, $0.8 \%$ (95\% CI: $0.6-1.2 \%)$ at Wave 3, and 1.4\% (95\% CI: $1.1-1.7 \%)$ at Wave 4, respectively. In addition, generally, the weighted prevalence of self-reported P30D cigarette smoking at follow-up waves was higher among adolescents who were older, sexual minorities, and those having severe internalizing or externalizing mental health problems at baseline waves. 
Table 2. Percentage of past-30-day (P30D) cigarette smoking at each follow-up wave by covariates at its corresponding baseline wave among baseline never cigarette smokers.

\begin{tabular}{|c|c|c|c|}
\hline \multirow[b]{2}{*}{ Covariates at Corresponding Baseline Wave } & \multicolumn{3}{|c|}{ P30D Cigarette Smoking at Follow-up Waves } \\
\hline & $\begin{array}{c}\text { Wave } 2(n=5001) \\
\%(95 \% \mathrm{CI})\end{array}$ & $\begin{array}{c}\text { Wave } 3(n=6637) \\
\quad \%(95 \% \mathrm{CI})\end{array}$ & $\begin{array}{c}\text { Wave } 4(n=8177) \\
\%(95 \% \mathrm{CI})\end{array}$ \\
\hline Total & $1.2(0.9-1.6)$ & $0.9(0.7-1.2)$ & $1.5(1.2-1.8)$ \\
\hline \multicolumn{4}{|l|}{ P30D e-cigarette use } \\
\hline Yes & $4.0(0.5-27.7)$ & $12.6(5.1-27.6)$ & $9.1(4.9-16.4)$ \\
\hline No & $1.2(0.9-1.6)$ & $0.8(0.6-1.2)$ & $1.4(1.1-1.7)$ \\
\hline \multicolumn{4}{|l|}{ Age group } \\
\hline $12-14$ & $1.1(0.8-1.6)$ & $0.7(0.5-1.1)$ & $0.9(0.6-1.2)$ \\
\hline $15-17$ & $1.9(0.6-5.9)$ & $1.7(1.2-2.5)$ & $2.6(2.0-3.5)$ \\
\hline \multicolumn{4}{|l|}{ Sex } \\
\hline Male & $0.8(0.5-1.3)$ & $0.6(0.4-1.0)$ & $1.7(1.3-2.1)$ \\
\hline Female & $1.6(1.1-2.2)$ & $1.3(0.9-1.8)$ & $1.4(1.0-1.9)$ \\
\hline \multicolumn{4}{|l|}{ Race/ethnicity } \\
\hline Non-Hispanic White & $1.3(0.9-2.0)$ & $1.3(0.9-1.8)$ & $1.9(1.4-2.5)$ \\
\hline Non-Hispanic Black & $0.5(0.2-1.7)$ & $0.3(0.1-0.8)$ & $0.8(0.4-1.7)$ \\
\hline Non-Hispanic Other & $1.1(0.4-3.2)$ & $1.1(0.4-2.9)$ & $1.0(0.5-1.8)$ \\
\hline Hispanic & $1.2(0.7-2.0)$ & $0.6(0.3-1.1)$ & $1.4(1.0-2.0)$ \\
\hline \multicolumn{4}{|l|}{ Sexual orientation (ages 14+) } \\
\hline Straight/Heterosexual & $1.7(1.0-2.7)$ & $1.0(0.7-1.6)$ & $2.0(1.5-2.5)$ \\
\hline Gay, lesbian, bisexual, or other & $4.7(1.6-12.9)$ & $3.3(1.5-7.1)$ & $5.3(3.4-8.3)$ \\
\hline \multicolumn{4}{|l|}{ Parental education } \\
\hline Less than high school & $1.5(0.8-2.8)$ & $0.6(0.3-1.5)$ & $2.1(1.4-3.0)$ \\
\hline High school graduate & $1.7(0.9-3.0)$ & $1.4(1.7-2.8)$ & $1.4(0.9-2.2)$ \\
\hline Some college or associate degree & $1.9(1.1-3.0)$ & $0.8(0.5-1.3)$ & $1.8(1.3-2.5)$ \\
\hline Bachelor's degree or above & $0.6(0.3-1.0)$ & $0.8(0.5-1.4)$ & $1.1(0.7-1.7)$ \\
\hline \multicolumn{4}{|l|}{ P30D use of other tobacco products 1} \\
\hline Yes & $4.5(0.5-30.8)$ & $8.7(2.2-29.0)$ & $12.7(6.1-24.8)$ \\
\hline No & $1.2(0.9-1.6)$ & $0.9(0.7-1.2)$ & $1.4(1.2-1.8)$ \\
\hline \multicolumn{4}{|l|}{ Past year internalizing problems } \\
\hline Low & $0.7(0.4-1.2)$ & $0.6(0.4-1.0)$ & $1.3(0.9-1.8)$ \\
\hline Moderate & $1.5(0.9-2.5)$ & $1.2(0.7-2.0)$ & $1.1(0.7-1.7)$ \\
\hline High & $1.8(1.1-3.0)$ & $1.4(0.8-2.4)$ & $2.6(1.9-3.5)$ \\
\hline \multicolumn{4}{|l|}{ Past year externalizing problems } \\
\hline Low & $0.4(0.2-0.9)$ & $0.6(0.4-1.0)$ & $1.1(0.8-1.6)$ \\
\hline Moderate & $1.1(0.6-2.0)$ & $0.8(0.4-1.6)$ & $1.2(0.8-1.9)$ \\
\hline High & $2.5(1.7-3.6)$ & $1.5(0.9-2.4)$ & $2.2(1.6-2.9)$ \\
\hline
\end{tabular}

${ }^{1}$ Other tobacco included cigars (traditional cigars, cigarillos, or filtered cigars), hookah, and smokeless tobacco (snus pouches, loose snus, moist snuff, dip, spit, or chewing tobacco).

\subsection{Multivariate Analyses}

As shown in Table 3, after adjusting for individual characteristics, adolescents who reported P30D e-cigarette use at baseline waves were significantly more likely to report P30D cigarette smoking in the follow-up waves (aOR $=3.90,95 \%$ CI: 2.51-6.08; $p<0.001$ ) (Model 1). Older age, P30D use of other tobacco products, and severe externalizing mental health problems at the baseline waves were also statistically significantly associated with elevated odds of P30D cigarette smoking at follow-up waves, everything else being constant. In addition, being Non-Hispanic Black or Other and having parents with a bachelor's degree or above were associated with reduced odds of P30D cigarette smoking at follow-up waves. As shown in Model 2, the interaction between P30D e-cigarette use and sex, noted as "P30D e-cigarette use \# Sex," was statistically significant (exponent of the estimated coefficients 3.18, 95\% CI: 2.21-4.57), which indicated that the associations between cigarette smoking status at 12-month follow-up waves and P30D e-cigarette use at baseline waves were significantly different between adolescent boys and girls. 
Table 3. Adjusted odds ratios (aORs) of P30D cigarette smoking at 12-month follow-up waves among adolescents (12-17 years of age) who were never cigarette smokers at baseline waves.

\begin{tabular}{|c|c|c|}
\hline & Model 1 & Model 2 \\
\hline & $\begin{array}{l}\text { No Interaction } \\
\text { aOR }(95 \% \text { CI })\end{array}$ & $\begin{array}{c}\text { With Interaction } \\
\text { aOR }(95 \% \text { CI) }\end{array}$ \\
\hline \multicolumn{3}{|l|}{ P30D e-cigarette use } \\
\hline Yes & $3.90(2.51-6.08)$ & $1.93(0.79-4.71)$ \\
\hline No & Ref. & Ref. \\
\hline \multicolumn{3}{|l|}{ Sex } \\
\hline Male & $1.24(1.03-1.49)$ & $1.19(0.98-1.43)$ \\
\hline Female & Ref. & Ref. \\
\hline \multicolumn{3}{|l|}{ P30D e-cigarette use \# Sex } \\
\hline Yes \# Male & & $3.18(2.21-4.57)$ \\
\hline No \# Female & & Ref. \\
\hline \multicolumn{3}{|l|}{ Age group } \\
\hline $12-14$ & Ref. & Ref. \\
\hline $15-17$ & $1.80(1.44-2.26)$ & $1.81(1.44-2.26)$ \\
\hline \multicolumn{3}{|l|}{ Race/ethnicity } \\
\hline Non-Hispanic White & Ref. & Ref. \\
\hline Non-Hispanic Black & $0.46(0.30-0.70)$ & $0.46(0.30-0.70)$ \\
\hline Non-Hispanic Other & $0.66(0.43-1.01)$ & $0.66(0.43-1.01)$ \\
\hline Hispanic & $0.66(0.50-0.89)$ & $0.66(0.50-0.89)$ \\
\hline \multicolumn{3}{|l|}{ Parental education } \\
\hline Less than high school & Ref. & Ref. \\
\hline High school graduate & $0.92(0.66-1.29)$ & $0.92(0.65-1.29)$ \\
\hline Some college or associate degree & $0.76(0.55-1.05)$ & $0.75(0.54-1.04)$ \\
\hline Bachelor's degree or above & $0.50(0.35-0.71)$ & $0.50(0.35-0.71)$ \\
\hline \multicolumn{3}{|l|}{ P30D use of other tobacco products 1} \\
\hline Yes & $3.22(1.23-8.46)$ & $3.45(1.36-8.70)$ \\
\hline No & Ref. & Ref. \\
\hline \multicolumn{3}{|l|}{ Internalizing mental health problems } \\
\hline Low & Ref. & Ref. \\
\hline Moderate & $1.33(1.04-2.58)$ & $1.33(1.05-1.69)$ \\
\hline High & $1.90(1.40-2.58)$ & $1.93(1.42-2.63)$ \\
\hline \multicolumn{3}{|l|}{ Externalizing mental health problems } \\
\hline Low & Ref. & Ref. \\
\hline Moderate & $1.40(1.01-1.95)$ & $1.41(1.01-1.97)$ \\
\hline High & $2.11(1.55-2.88)$ & $2.09(1.54-2.85)$ \\
\hline
\end{tabular}

${ }^{1}$ Other tobacco included cigars (traditional cigars, cigarillos, or filtered cigars), hookah, and smokeless tobacco (snus pouches, loose snus, moist snuff, dip, spit, or chewing tobacco). Ref.: reference group.

Table 4 showed the results of the subgroup analyses stratified by sex. For boys, P30D cigarette smoking at 12-month follow-up waves was statistically significantly associated with P30D e-cigarette use at baseline waves ( $\mathrm{aOR}=6.17,95 \% \mathrm{CI}: 2.43-15.68 ; p<0.001)$, controlling for individual characteristics. However, for girls, the corresponding association was not statistically significant ( $\mathrm{aOR}=1.10,95 \%$ CI: $0.14-8.33 ; p=0.154$ ), controlling for other covariates.

Table 4. Adjusted odds ratios (aORs) ${ }^{1}$ from subgroup analysis for adolescent boys and girls.

\begin{tabular}{|c|c|c|}
\hline & Boys P30D Cigarette Smoking & Girls P30D Cigarette Smoking \\
\hline & aOR $(95 \% \mathrm{CI})$ & aOR $(95 \% \mathrm{CI})$ \\
\hline \multicolumn{3}{|c|}{ P30D e-cigarette use } \\
\hline Yes & $6.17(2.43-15.68)$ & $1.10(0.14-8.33)$ \\
\hline No & Ref. & Ref. \\
\hline
\end{tabular}

${ }^{1}$ Controlling for age, race/ethnicity, parental education, P30D other tobacco use, past-year internalizing mental health problems, and past-year externalizing mental health problems. Ref.: reference group. 
To evaluate whether the association between e-cigarette use and subsequent cigarette smoking is robust to outcome measures, sensitivity analyses in which cigarette smoking was measured by ever cigarette smoking, rather than P30D cigarette smoking at 12-month follow-up waves, were conducted. The results of the sensitivity analyses were presented in Tables S2-S4. Consistent with results presented in Table 2, results in Table S2 show that, at each follow-up wave, the prevalence of ever cigarette smoking was higher among adolescents who reported P30D e-cigarette use at corresponding baseline wave, compared with those who did not. In addition, results in Table S3 were similar to those in Table 3 regarding the adjusted associations between ever cigarette smoking at 12-month follow-up waves and characteristics at baseline waves. Notably, the interaction term between ecigarette use and sex (P30D e-cigarette use \# Sex) was also statistically significant, consistent with the results in Table 3. Furthermore, the results of subgroup analyses in Table S4 showed that the adjusted ORs between ever cigarette smoking at 12-month follow-up waves and P30D e-cigarette use at baseline waves were 5.81 (95\% CI: 3.34-10.13; $p<0.001)$ and 2.31 (95\% CI: $0.98-5.41 ; p=0.052)$ for adolescent boys and girls, respectively.

\section{Discussion}

This study aimed to examine whether and to what extent sex would affect the associations between initial e-cigarette use and subsequent cigarette smoking among American adolescents (aged 12-17). Although the longitudinal associations between e-cigarette use and subsequent cigarette smoking had been documented [8-10], no previous studies examined the potential difference in this relationship by sex. Our results revealed, consistent with previous studies, that e-cigarettes use at baseline waves was significantly associated with P30D cigarette smoking at 12-month follow-up waves. More importantly, our study added to the current knowledge base by revealing that this association was significantly stronger for boys than for girls. The differential patterns were consistently observed regardless of whether the follow-up cigarette smoking status was measured by past 30-day use or ever use. The consistency indicates that sex differences in the association between initial P30D e-cigarette use and subsequent cigarette smoking are robust to outcome measures.

The differential effects characterized by sex may be partially attributable to the different levels of nicotine dependence between boys and girls. Our study showed that among P30D e-cigarette users, the number of days using e-cigarettes in the past 30 days were higher for boys than for girls (Table S5). The difference may indicate that among adolescents who used e-cigarettes, the level of nicotine dependence was likely to be higher for boys than girls. This finding is consistent with a recent literature review concluding that boys tended to use e-cigarettes more frequently than girls [35]. Since youth with higher nicotine dependence levels were presumably more likely to transition to cigarette smoking, the difference in nicotine dependence between e-cigarette using boys and girls may explain why e-cigarette using boys were more likely to advance to cigarette smoking than e-cigarette using girls [10]. In addition to use frequency, several other potential reasons may explain why boys may be more likely to develop nicotine dependency than girls from vaping. First, evidence showed that females metabolized nicotine faster than males due to estrogen [16]. The differential metabolism rates by sex suggests that females are more likely to experience higher adverse sensitivity and lower rewarding effects of nicotine than their male counterparts [36-38]. Consequently, e-cigarette using girls may be less likely to develop nicotine dependency and less susceptible to transition to cigarette smoking. In addition, the sources of acquisition for e-cigarettes may be different between girls and boys. A study in Connecticut showed that compared with boys, girls were more likely to obtain e-cigarettes from their peers [39], suggesting more social and less frequent e-cigarette use among girls; hence, the difference in transitioning to cigarette smoking. The sex differences in the association between baseline e-cigarette use and subsequent cigarette initiation suggest that policies/interventions aiming to combat the youth vaping epidemic may reduce subsequent cigarette smoking among the U.S. youth population, particularly among adolescent boys. For example, a vaping cessation media campaign that specifically 
targets at boys may reduce e-cigarette use among boys, and consequently, making them less likely to transition from e-cigarettes to cigarettes.

Our results also show that internalizing and externalizing mental health problems were prospectively associated with cigarette smoking initiation, controlling for sociodemographic covariates and use of e-cigarettes and other tobacco products. Our findings were consistent with other published studies [21,40], suggesting that a wide range of mental health problems could be considered as predictors of cigarette smoking among adolescents. Early screening for mental health problems combined with targeted mental health interventions (e.g., school counseling, preventive efforts through primary care providers) may help reduce cigarette smoking among vulnerable youth [41,42].

Additionally, we found that older age, being Non-Hispanic White, and using other tobacco products were significantly associated with subsequent cigarette smoking in our study, consistent with findings reported in previous studies $[8,10,29,32]$. Notably, the magnitude of the association between P30D e-cigarette use at baseline waves and subsequent cigarette smoking was comparable to the association between P30D other tobacco use at baseline waves and subsequent cigarette smoking, indicating the importance of e-cigarette use in predicting subsequent cigarette smoking among U.S. adolescents. Continued surveillance of e-cigarette and other tobacco product use among youth is, therefore, warranted.

This study is subject to several limitations. First, self-reported use of e-cigarettes, cigarettes, and other tobacco products may introduce recall bias and social desirability bias [43]. Second, the small sample size of adolescent e-cigarette users in the PATH study prevented us from conducting a mediation analysis to further examine whether the sex differences could be partially attributed to different nicotine dependence levels between boys and girls. Future studies are needed to explore the mechanisms of the differential effects characterized by sex and other potential characteristics. Third, the association between e-cigarette use at baseline waves and subsequent cigarette smoking identified in this study did not represent a true causal relationship. However, our study did control for a wide range of potential confounding factors and established a temporal relationship and chronological sequence between e-cigarette use and subsequent cigarette smoking, addressing most, if not all, of the concerns and criticisms on the current literature regarding the potential gateway effect of e-cigarettes to cigarette smoking [5,44-46].

\section{Conclusions}

This study's findings highlighted the important sex differences in the longitudinal association between initial e-cigarette use and subsequent cigarette smoking among U.S. adolescents. Efforts to curb the adolescent vaping epidemic may have added benefits to reduce cigarette initiation, particularly among adolescent boys. Sex-specific tobacco control interventions may be warranted to reduce youth tobacco use. In addition, targeted tobacco control interventions, focusing on youth with severe mental health conditions, are warranted. Finally, continued efforts are needed to monitor tobacco and cigarette transitions among youth, particularly among vulnerable and high-risk youth subpopulations.

Supplementary Materials: The following are available online at https:/ /www.mdpi.com/1660-460 1/18/4/1695/s1, Table S1: Items for internalizing and externalizing mental health problems, Table S2: Percentage of ever cigarette smoking at each follow-up wave by covariates at its corresponding baseline wave among baseline never cigarette smokers, Table S3: Adjusted odds ratios (aORs) of ever cigarette smoking at 12-month follow-up waves among adolescents (12-17 years of age) who were never cigarette smokers at baseline waves, Table S4: Adjusted odds ratios (aORs) from subgroup analysis for adolescent boys and girls, Table S5: E-cigarette dependence among P30D e-cigarette users for adolescent boys and girls (aged 12-17).

Author Contributions: Conceptualization, Z.D. and J.H.; methodology, Z.D., J.H., and Y.W.; formal analysis, Z.D. and Y.W.; writing—original draft preparation, Z.D.; writing—review and editing, Z.D., Y.W., and J.H.; project administration J.H., Z.D., and Y.W.; funding acquisition, J.H. All authors have read and agreed to the published version of the manuscript. 
Funding: This research was funded by the National Institutes of Health (NIH), grant number R01CA194681.

Institutional Review Board Statement: Ethical review and approval were waived for this study, because this study involved only secondary data analysis of de-identified PATH survey data, which was deemed as a non-human subject study by the Georgia State University Institutional Review Board (GSU-IRB).

Informed Consent Statement: Informed consent was obtained from all subjects involved in the study.

Data Availability Statement: Publicly available datasets were analyzed in this study. This data can be found here: [https:/ /www.icpsr.umich.edu/icpsrweb/NAHDAP/search/studies?q=PATH (accessed on 20 March 2020)]

Conflicts of Interest: The authors declare no conflict of interest.

\section{References}

1. U.S. Department of Health and Human Services. The Health Consequences of Smoking - 50 Years of Progress: A Report of the Surgeon General; U.S. Department of Health and Human Services, Centers for Disease Control and Prevention, National Center for Chronic Disease Prevention and Health Promotion, Office on Smoking and Health: Atlanta, GA, USA, 2014.

2. Johnston, L.D.; Miech, R.A.; O'Malley, P.M.; Bachman, J.G.; Schulenberg, J.E.; Patrick, M.E. Monitoring the Future National Survey Results on Drug Use, 1975-2018: Overview, Key Findings on Adolescent Drug Use; University of Michigan, Institute for Social Research (ISR): Ann Arbor, MI, USA, 2019.

3. National Institute on Drug Abuse. Study: Surge of Teen Vaping Levels off, but Remains High as of Early 2020. Available online: https: / www.drugabuse.gov/news-events/news-releases/2020/12/study-surge-of-teen-vaping-levels-off-but-remainshigh-as-of-early-2020 (accessed on 27 January 2021).

4. U.S. Department of Health and Human Services. E-Cigarette Use among Youth and Young Adults: A Report of the Surgeon General; U.S. Department of Health and Human Services, Centers for Disease Control and Prevention, National Center for Chronic Disease Prevention and Health Promotion, Office on Smoking and Health: Atlanta, GA, USA, 2016.

5. Khouja, J.N.; Suddell, S.F.; Peters, S.E.; Taylor, A.E.; Munafò, M.R. Is e-cigarette use in non-smoking young adults associated with later smoking? A systematic review and meta-analysis. Tob. Control 2020. [CrossRef]

6. Huang, J.; Duan, Z.; Kwok, J.; Binns, S.; Vera, L.E.; Kim, Y.; Szczypka, G.; Emery, S.L. Vaping versus JUULing: How the extraordinary growth and marketing of JUUL transformed the US retail e-cigarette market. Tob. Control 2019, 28, 146-151. [CrossRef] [PubMed]

7. Wang, T.W.; Neff, L.J.; Park-Lee, E.; Ren, C.; Cullen, K.A.; King, B.A. E-cigarette use among middle and high school studentsUnited States, 2020. Morb. Mortal. Wkly. Rep. 2020, 69, 1310. [CrossRef] [PubMed]

8. Soneji, S.; Barrington-Trimis, J.L.; Wills, T.A.; Leventhal, A.M.; Unger, J.B.; Gibson, L.A.; Yang, J.; Primack, B.A.; Andrews, J.A.; Miech, R.A. Association between initial use of e-cigarettes and subsequent cigarette smoking among adolescents and young adults: A systematic review and meta-analysis. JAMA Pediatr. 2017, 171, 788-797. [CrossRef]

9. Leventhal, A.M.; Strong, D.R.; Kirkpatrick, M.G.; Unger, J.B.; Sussman, S.; Riggs, N.R.; Stone, M.D.; Khoddam, R.; Samet, J.M.; Audrain-McGovern, J. Association of electronic cigarette use with initiation of combustible tobacco product smoking in early adolescence. JAMA 2015, 314, 700-707. [CrossRef]

10. Primack, B.A.; Soneji, S.; Stoolmiller, M.; Fine, M.J.; Sargent, J.D. Progression to traditional cigarette smoking after electronic cigarette use among US adolescents and young adults. JAMA Pediatr. 2015, 169, 1018-1023. [CrossRef]

11. Amos, A.; Greaves, L.; Nichter, M.; Bloch, M. Women and tobacco: A call for including gender in tobacco control research, policy and practice. Tob. Control 2012, 21, 236-243. [CrossRef]

12. Solomon, A. Gender, women, and the future of tobacco control. Drugs Alcohol Today 2020. [CrossRef]

13. Regitz-Zagrosek, V. Sex and gender differences in health: Science \& Society Series on Sex and Science. EMBO Rep. 2012, 13, 596-603. [CrossRef] [PubMed]

14. Pogun, S.; Yararbas, G. Sex differences in nicotine action. Nicotine Psychopharmacol. 2009, 261-291.

15. Schmidt, H.D.; Rupprecht, L.E.; Addy, N.A. Neurobiological and neurophysiological mechanisms underlying nicotine seeking and smoking relapse. Mol. Neuropsychiatry 2018, 4, 169-189. [CrossRef] [PubMed]

16. Benowitz, N.L.; Lessov-Schlaggar, C.N.; Swan, G.E.; Jacob, P., III. Female sex and oral contraceptive use accelerate nicotine metabolism. Clin. Pharmacol. Ther. 2006, 79, 480-488. [CrossRef] [PubMed]

17. Cosgrove, K.P.; Wang, S.; Kim, S.-J.; McGovern, E.; Nabulsi, N.; Gao, H.; Labaree, D.; Tagare, H.D.; Sullivan, J.M.; Morris, E.D. Sex differences in the brain's dopamine signature of cigarette smoking. J. Neurosci. 2014, 34, 16851-16855. [CrossRef]

18. Jacobs, W.; Goodson, P.; Barry, A.E.; McLeroy, K.R. The role of gender in adolescents' social networks and alcohol, tobacco, and drug use: A systematic review. J. Sch. Health 2016, 86, 322-333. [CrossRef] [PubMed]

19. Waldron, I. Patterns and causes of gender differences in smoking. Soc. Sci. Med. 1991, 32, 989-1005. [CrossRef]

20. Piper, M.E.; Cook, J.W.; Schlam, T.R.; Jorenby, D.E.; Smith, S.S.; Bolt, D.M.; Loh, W.-Y. Gender, race, and education differences in abstinence rates among participants in two randomized smoking cessation trials. Nicotine Tob. Res. 2010, 12, 647-657. [CrossRef] 
21. Riehm, K.E.; Young, A.S.; Feder, K.A.; Krawczyk, N.; Tormohlen, K.N.; Pacek, L.R.; Mojtabai, R.; Crum, R.M. Mental health problems and initiation of e-cigarette and combustible cigarette use. Pediatrics 2019, 144. [CrossRef]

22. Upadhyaya, H.P.; Deas, D.; Brady, K.T.; Kruesi, M. Cigarette smoking and psychiatric comorbidity in children and adolescents. J. Am. Acad. Child Adolesc. Psychiatry 2002, 41, 1294-1305. [CrossRef]

23. Audrain-McGovern, J.; Rodriguez, D.; Kassel, J.D. Adolescent smoking and depression: Evidence for self-medication and peer smoking mediation. Addiction 2009, 104, 1743-1756. [CrossRef]

24. National Institute on Drug Abuse; Food and Drug Administration Center for Tobacco Products. Population Assessment of Tobacco and Health (PATH) Study [United States] Public-Use Files. Inter-University Consortium for Political and Social Research [Distributor]; National Institutes of Health National Institute on Drug Abuse: Bethesda, MD, USA, 2020.

25. Hyland, A.; Ambrose, B.K.; Conway, K.P.; Borek, N.; Lambert, E.; Carusi, C.; Taylor, K.; Crosse, S.; Fong, G.T.; Cummings, K.M. Design and methods of the Population Assessment of Tobacco and Health (PATH) Study. Tob. Control 2017, 26, 371-378. [CrossRef]

26. Inter-University Consortium for Political and Social Research. Population Assessment of Tobacco and Health (PATH) Study [United States] Public-Use Files ICPSR Public-Use Files User Guide. Available online: https:/ /www.icpsr.umich.edu/files/ NAHDAP/documentation/ug36498-all.pdf (accessed on 21 January 2021).

27. National Institute on Drug Abuse; Food Drug Administration Center for Tobacco Products. Population Assessment of Tobacco and Health (PATH) Study [United States] Restricted-Use Files. Inter-university Consortium for Political and Social Research [distributor]; National Institutes of Health National Institute on Drug Abuse: Atlanta, GA, USA, 2020.

28. Von Elm, E.; Altman, D.G.; Egger, M.; Pocock, S.J.; Gøtzsche, P.C.; Vandenbroucke, J.P. The Strengthening the Reporting of Observational Studies in Epidemiology (STROBE) statement: Guidelines for reporting observational studies. Ann. Intern. Med. 2007, 147, 573-577. [CrossRef]

29. Kasza, K.A.; Edwards, K.C.; Tang, Z.; Stanton, C.A.; Sharma, E.; Halenar, M.J.; Taylor, K.A.; Donaldson, E.; Hull, L.C.; Day, $\mathrm{H}$. Correlates of tobacco product initiation among youth and adults in the USA: Findings from the PATH Study Waves 1-3 (2013-2016). Tob. Control 2020, 29, s191-s202. [CrossRef]

30. Kasza, K.A.; Edwards, K.C.; Tang, Z.; Stanton, C.A.; Sharma, E.; Halenar, M.J.; Taylor, K.A.; Donaldson, E.A.; Hull, L.C.; Bansal-Travers, M. Correlates of tobacco product cessation among youth and adults in the USA: Findings from the PATH Study Waves 1-3 (2013-2016). Tob. Control 2020, 29, s203-s215. [CrossRef] [PubMed]

31. Edwards, K.C.; Kasza, K.A.; Tang, Z.; Stanton, C.A.; Sharma, E.; Halenar, M.J.; Taylor, K.A.; Donaldson, E.A.; Hull, L.C.; Bansal-Travers, M. Correlates of tobacco product reuptake and relapse among youth and adults in the USA: Findings from the PATH Study Waves 1-3 (2013-2016). Tob. Control 2020, 29, s216-s226. [CrossRef]

32. Stanton, C.A.; Sharma, E.; Seaman, E.L.; Kasza, K.A.; Edwards, K.C.; Halenar, M.J.; Taylor, K.A.; Day, H.; Anic, G.; Hull, L.C. Initiation of any tobacco and five tobacco products across 3 years among youth, young adults and adults in the USA: Findings from the PATH Study Waves 1-3 (2013-2016). Tob. Control 2020, 29, s178-s190. [CrossRef] [PubMed]

33. Conway, K.P.; Green, V.R.; Kasza, K.A.; Silveira, M.L.; Borek, N.; Kimmel, H.L.; Sargent, J.D.; Stanton, C.; Lambert, E.; Hilmi, N. Co-occurrence of tobacco product use, substance use, and mental health problems among adults: Findings from Wave 1 (2013-2014) of the Population Assessment of Tobacco and Health (PATH) Study. Drug Alcohol Depend. 2017, 177, 104-111. [CrossRef] [PubMed]

34. Conway, K.P.; Green, V.R.; Kasza, K.A.; Silveira, M.L.; Borek, N.; Kimmel, H.L.; Sargent, J.D.; Stanton, C.A.; Lambert, E.; Hilmi, N. Co-occurrence of tobacco product use, substance use, and mental health problems among youth: Findings from wave 1 (2013-2014) of the population assessment of tobacco and health (PATH) study. Addict. Behav. 2018, 76, 208-217. [CrossRef]

35. Kong, G.; Kuguru, K.E.; Krishnan-Sarin, S. Gender differences in US adolescent e-cigarette use. Curr. Addict. Rep. 2017, 4, 422-430. [CrossRef]

36. Perkins, K.A. Acute responses to nicotine and smoking: Implications for prevention and treatment of smoking in lower SES women. Drug Alcohol Depend. 2009, 104, S79-S86. [CrossRef]

37. Sofuoglu, M.; Mooney, M. Subjective responses to intravenous nicotine: Greater sensitivity in women than in men. Exp. Clin. Psychopharmacol. 2009, 17, 63. [CrossRef]

38. Rubinstein, M.L.; Shiffman, S.; Rait, M.A.; Benowitz, N.L. Race, gender, and nicotine metabolism in adolescent smokers. Nicotine Tob. Res. 2013, 15, 1311-1315. [CrossRef]

39. Kong, G.; Morean, M.E.; Cavallo, D.A.; Camenga, D.R.; Krishnan-Sarin, S. Sources of electronic cigarette acquisition among adolescents in Connecticut. Tob. Regul. Sci. 2017, 3, 10-16. [CrossRef]

40. Green, V.R.; Conway, K.P.; Silveira, M.L.; Kasza, K.A.; Cohn, A.; Cummings, K.M.; Stanton, C.A.; Callahan-Lyon, P.; Slavit, W.; Sargent, J.D. Mental health problems and onset of tobacco use among 12-to 24-year-olds in the PATH study. J. Am. Acad. Child Adolesc. Psychiatry 2018, 57, 944-954.e944. [CrossRef] [PubMed]

41. Flay, B.R. School-based smoking prevention programs with the promise of long-term effects. Tob. Induc. Dis. 2009, 5, 6. [CrossRef] [PubMed]

42. Kulig, J.W. Tobacco, alcohol, and other drugs: The role of the pediatrician in prevention, identification, and management of substance abuse. Pediatrics 2005, 115, 816-821. [CrossRef]

43. Coughlin, S.S. Recall bias in epidemiologic studies. J. Clin. Epidemiol. 1990, 43, 87-91. [CrossRef] 
44. Chapman, S.; Bareham, D.; Maziak, W. The gateway effect of e-cigarettes: Reflections on main criticisms. Nicotine Tob. Res. 2019, 21, 695-698. [CrossRef] [PubMed]

45. Shahab, L.; Beard, E.; Brown, J. Association of initial e-cigarette and other tobacco product use with subsequent cigarette smoking in adolescents: A cross-sectional, matched control study. Tob. Control 2020. [CrossRef]

46. Morgenstern, M.; Nies, A.; Goecke, M.; Hanewinkel, R. E-Cigarettes and the Use of Conventional Cigarettes: A cohort study in 10th grade students in Germany. Dtsch. Ärzteblatt Int. 2018, 115, 243. [CrossRef] 